1. Wenzel S, Castro M, Corren J, et al. Dupilumab efficacy and safety in adults with uncontrolled persistent asthma despite use of medium-to-high-dose inhaled corticosteroids plus a long-acting beta-agonist: a pivotal dose-ranging study. Lancet 2016;388:31-44.
2. Bachert C, Mannent L, Naclerio RM, et al. Effect of subcutaneous dupilumab on nasal polyp burden in patients with chronic sinusitis and nasal polyposis: a randomized clinical trial. JAMA 2016;315:469-79. DOI: 10.1056/NEJMc1700366

\title{
Short-Term versus Long-Term Blood Storage
}

TO THE EDITOR: In the Informing Fresh versus Old Red Cell Management (INFORM) study, Heddle et al. (Nov. 17 issue) ${ }^{1}$ suggest that the debate over red-cell storage and outcome after transfusion is now closed. According to the accompanying editorial, ${ }^{2}$ there may no longer be an issue regarding the freshness of red cells for transfusion. Although we admire the quality of all five recent, large cited studies on this topic ${ }^{2}$ (which have covered such diverse topics as the relationship between the age of blood and type of processing to patients' outcomes), we consider this conclusion to be questionable.

Previous studies have stressed the safety and survival benefit of a restrictive policy versus a liberal policy for red-cell transfusion, which suggests a downside to such transfusion. ${ }^{3}$ Red-cell storage lesions may explain this observation. Stored red cells have both reversible and irreversible lesions; the latter occur from the second week onward. ${ }^{4}$ However, recent studies have compared red cells that were stored for 7 to 10 days with those that were stored for 15 to 20 days in other words, comparing old red cells with older red cells. Other studies have suggested that the transfusion of blood from donors who have characteristics associated with storage problems (so-called bad donors) ${ }^{5}$ has resulted in poor outcomes among the recipients, an effect that was not analyzed in the current trials. We thus encourage the continuation of trials of really fresh versus stored red cells and the identification of donor characteristics associated with good recipient outcomes.

Olivier Garraud, M.D., Ph.D.

Institut National de la Transfusion Sanguine

Paris, France

ogarraud@ints.fr

Jean-Daniel Tissot, M.D., Ph.D.

Transfusion Interrégionale Croix Rouge Suisse Epalinges, Switzerland

\author{
Alexander P. Vlaar, M.D., Ph.D. \\ Academic Medical Center \\ Amsterdam, the Netherlands
}

No potential conflict of interest relevant to this letter was reported.

1. Heddle NM, Cook RJ, Arnold DM, et al. Effect of short-term vs. long-term blood storage on mortality after transfusion. N Engl J Med 2016;375:1937-45.

2. Tobian AA, Ness PM. Red cells - aging gracefully in the blood bank. N Engl J Med 2016;375:1995-7.

3. Holst LB, Petersen MW, Haase N, Perner A, Wetterslev J. Restrictive versus liberal transfusion strategy for red blood cell transfusion: systematic review of randomised trials with metaanalysis and trial sequential analysis. BMJ 2015;350:h1354.

4. Prudent M, Tissot JD, Lion N. In vitro assays and clinical trials in red blood cell aging: lost in translation. Transfus Apher Sci 2015;52:270-6.

5. Chassé M, McIntyre L, English SW, et al. Effect of blood donor characteristics on transfusion outcomes: a systematic review and meta-analysis. Transfus Med Rev 2016;30:69-80

DOI: $10.1056 /$ NEJMc1700464

TO THE EDITOR: The study by Heddle and colleagues is limited in what it actually addresses by design, since it specifically shows only that the length of red-cell storage is immaterial to mortality in the context of the current practice of red-cell transfusion aggregated across diverse clinical settings. Given that design, the study does not address whether any of the transfusions were essential, since most of the patients at highest risk were excluded. Therefore, it is uncertain whether a between-group difference could have been detected. Without knowing whether the study design could have detected a true difference, it remains possible that an important association between storage length and outcomes exists.

There remains much controversy as to when and in which clinical settings transfusions are clearly beneficial to mortality, ${ }^{1,2}$ with wide variability in transfusion practice ${ }^{3}$ and, arguably, still much overuse. This study leaves unaddressed important questions - notably, whether storage 
length matters when transfusions are clearly indicated or life-sustaining and whether the age of blood matters with respect to measures other than death.

Robert J. Meyer, M.D.

University of Virginia School of Medicine

Charlottesville, VA

rjm7cd@virginia.edu

No potential conflict of interest relevant to this letter was reported.

1. Carson JL, Stanworth SJ, Roubinian N, et al. Transfusion thresholds and other strategies for guiding allogeneic red blood cell transfusion. Cochrane Database Syst Rev 2016;10:CD002042. 2. Holst LB, Petersen MW, Haase N, Perner A, Wetterslev J. Restrictive versus liberal transfusion strategy for red blood cell transfusion: systematic review of randomised trials with metaanalysis and trial sequential analysis. BMJ 2015;350:h1354.

3. Frank SM, Savage WJ, Rothschild JA, et al. Variability in blood and blood component utilization as assessed by an anesthesia information management system. Anesthesiology 2012; 117:99-106.

DOI: $10.1056 /$ NEJMc1700464

TO THE EDITOR: Heddle et al. report no significant between-group difference in the rate of death according to the duration of blood storage among patients in a general hospital population who underwent transfusion. However, the authors overlooked factors affecting red-cell quality, including the donor's sex, age, and frequency of donation.

Raval et al. ${ }^{1}$ have suggested that the mechanical fragility and hemolysis of red cells is correlated with the donor's sex and age. Heritable donor factors can also influence the susceptibility of stored red cells to oxidative injury. ${ }^{2}$ In addition, methods of red-cell collection and processing may affect the quality of transfused blood.

Transfusion research should not only evaluate the effect of donated blood according to the length of storage time but also analyze the personal characteristics of the donors. Also, such research should focus on more accurate red-cell quality metrics, such as hemoglobin content, percent hemolysis, $\mathrm{pH}$, and levels of lactate, electrolytes, and 2,3-bisphosphoglyceric acid.

Hai Zou, M.D.

Jie Pang, M.D.

Xian-Da Che, M.D.

Zhejiang Provincial People's Hospital

Hangzhou, China

haire1993@163.com
No potential conflict of interest relevant to this letter was reported.

1. Raval JS, Waters JH, Seltsam A, et al. The use of the mechanical fragility test in evaluating sublethal RBC injury during storage. Vox Sang 2010;99:325-31.

2. van 't Erve TJ, Doskey CM, Wagner BA, et al. Heritability of glutathione and related metabolites in stored red blood cells. Free Radic Biol Med 2014;76:107-13.

DOI: 10.1056/NEJMc1700464

TO THE EDITOR: Although the findings of the INFORM study provide reassurance regarding mortality associated with the transfusion of older blood, the question of morbidity (specifically, infection) was not addressed in the article. The prolonged storage of blood is associated with increased levels of potentially toxic, free nontransferrin-bound iron (NTBI), which accumulates progressively as blood ages, reaching maximal levels after approximately 35 days of storage. ${ }^{1}$ Increased NTBI runs counter to the natural inflammatory response that decreases serum iron to protect against infection. ${ }^{2}$ Indeed, an increased infection risk with a longer duration of blood storage has been suggested by a number of studies, but a lack of evidence has precluded consensus. ${ }^{3}$ Further clarity on this matter may be important for the correct selection of blood for use in patients with either an active infection or an increased susceptibility to infection.

John D. Ryan, M.B., B.S., Ph.D.

Royal Free Hospital

London, United Kingdom

john.ryan@ndm.ox.ac.uk

Hal Drakesmith, Ph.D.

University of Oxford

Oxford, United Kingdom

No potential conflict of interest relevant to this letter was reported.

1. Collard K, White D, Copplestone A. The influence of storage age on iron status, oxidative stress and antioxidant protection in paediatric packed cell units. Blood Transfus 2014;12:210-9.

2. Drakesmith H, Prentice AM. Hepcidin and the iron-infection axis. Science 2012;338:768-72.

3. Lelubre C, Vincent JL. Relationship between red cell storage duration and outcomes in adults receiving red cell transfusions: a systematic review. Crit Care 2013;17:R66.

DOI: 10.1056/NEJMc1700464

THE AUTHORS REPLY: The correspondents raise issues about the effect of blood characteristics other than storage duration, as well as concerns about nonfatal outcomes, various definitions of 
fresh and old blood, and the effects of extreme storage durations. The INFORM study was designed to assess the effect of blood-storage duration on in-hospital mortality, not the effect of donor characteristics, donation frequency, wholeblood processing method, or product quality. However, data from our study provide an opportunity for exploratory analyses to investigate some of these issues.

Ryan and Drakesmith express an interest in infectious complications, data that were not captured in the pragmatic design of our study. A meta-analysis of four trials that examined infection outcomes showed an increased risk of infection when fresher blood was transfused, although the quality of the evidence was low. ${ }^{1}$ We await the results of two ongoing studies, Standard Issue Transfusion versus Fresher Red Blood Cell Use in Intensive Care - A Randomized Controlled Trial (TRANSFUSE-RCT) ${ }^{2}$ and the Age of Blood in Children in Pediatric Intensive Care Units (ABC PICU), ${ }^{3}$ to determine whether the results are consistent with this finding.

Meyer raises the question of whether the effect of older versus fresher blood could be different for patients receiving transfusions that were not clinically indicated. If such patients were included in our study, it is possible that estimated effects of fresher versus older blood could be attenuated. However, the results of studies involving more critically ill patients are consistent with our findings, ${ }^{1}$ and a treatment effect was not seen in our subgroup analysis of the sicker patients. Putative harms associated with the transfusion of older blood are not directly related to the putative benefits of transfusion. Transfusions presumably improve clinical recovery from illness and reduce the risk of secondary complications, including myocardial ischemia. In contrast, concerns about the effect of older blood relate to harm that could be the result of structural, biochemical, or immunologic changes that are described as the red-cell storage lesion.

During a 42-day storage period, the designation of fresh blood and old blood is subjective. The pragmatic nature of the INFORM study meant that thresholds defining fresh or old blood were not specified, since patients who had undergone randomization received the freshest or oldest blood that was available. The distributions of the length of blood storage in each treatment group are provided in Table 2 of our article (available with the full text at NEJM.org). On the basis of our study design, it is not possible to make causal statements about the effect of consistent exposure to blood of a particular storage duration. Additional analyses of our data may provide evidence regarding the effect of exposure to blood stored for a maximum of 1 to 7 days as compared with blood stored for 35 to 42 days.

Nancy M. Heddle, M.Sc.

McMaster University

Hamilton, ON, Canada

heddlen@mcmaster.ca

Richard J. Cook, Ph.D.

University of Waterloo

Waterloo, ON, Canada

John W. Eikelboom, M.D.

Population Health Research Institute

Hamilton, ON, Canada

Since publication of their article, the authors report no further potential conflict of interest.

1. Alexander PE, Barty R, Fei Y, et al. Transfusion of fresher vs older red blood cells in hospitalized patients: a systematic review and meta-analysis. Blood 2016;127:400-10.

2. Aubron C, Syres G, Nichol A, et al. A pilot feasibility trial of allocation of freshest available red blood cells versus standard care in critically ill patients. Transfusion 2012;52:1196-202.

3. Age of Blood in Children in Pediatric Intensive Care Units (ABC PICU). Clinical-Trials.gov, 2013 (https://clinicaltrials.gov/ ct2/show/NCT01977547).

DOI: 10.1056/NEJMc1700464

THE EDITORIALISTS REPLY: In response to the comments of Garraud et al.: we appreciate the perspective that issues regarding the storage duration of red cells remain. The safety of red cells that are transfused during the last week of storage should be evaluated, ${ }^{1,2}$ perhaps by secondary analyses of published trials. However, it would be extremely difficult to enroll enough patients from specialized populations (e.g., those with trauma or massive transfusion) to provide sufficient statistical power for a randomized trial. Among 14 randomized trials enrolling more than 35,000 patients, not one has shown that the transfusion of older red cells resulted in worse outcomes. The AABB (formerly, the American Association of Blood Banks) recently issued a strong recommendation based on moderate-quality evidence that red cells transfused at any point in their licensed dating period are safe. ${ }^{3}$ Previous trials 
have also shown that subgroup effects are often spurious and that specialized patient populations generally follow the same trend as that in the general population. ${ }^{4}$ In the era of shrinking research budgets, it is even more important to strategically focus research in areas that will have the greatest clinical effect. Another trial evaluating the duration of red-cell storage would not meet that target.

Aaron A.R. Tobian, M.D., Ph.D.

Paul M. Ness, M.D.

Johns Hopkins University

Baltimore, MD

atobian1@jhmi.edu
Since publication of their editorial, the authors report no further potential conflict of interest.

1. Rapido F, Brittenham GM, Bandyopadhyay S, et al. Prolonged red cell storage before transfusion increases extravascular hemolysis. J Clin Invest 2017;127:375-82.

2. Goel R, Johnson DJ, Scott AV, et al. Red blood cells stored 35 days or more are associated with adverse outcomes in high-risk patients. Transfusion 2016;56:1690-8.

3. Carson JL, Guyatt G, Heddle NM, et al. Clinical practice guidelines from the AABB: red blood cell transfusion thresholds and storage. JAMA 2016;316:2025-35.

4. Sun X, Ioannidis JP, Agoritsas T, Alba AC, Guyatt G. How to use a subgroup analysis: users' guide to the medical literature. JAMA 2014;311:405-11.

DOI: 10.1056/NEJMc1700464

\section{Hypothermia for Convulsive Status Epilepticus}

TO THE EDITOR: In the HYBERNATUS (Hypothermia for Brain Enhancement Recovery by Neuroprotective and Anticonvulsivant Action after Convulsive Status Epilepticus) trial, Legriel et al. (Dec. 22 issue) ${ }^{1}$ did not find a beneficial effect of induced hypothermia on functional outcomes at 90 days among patients with convulsive status epilepticus. These results should be revisited with regard to the three potential benefits of induced hypothermia: neuroprotection, seizure treatment, ${ }^{2}$ and lowering of intracranial pressure. ${ }^{3}$

The neuroprotective effect of hypothermia was not significant, but the trial showed a clear antiepileptic benefit, in that hypothermia lowered the rate of progression to electroencephalogram (EEG)-confirmed status epilepticus. Although $25 \%$ of the patients had refractory status epilepticus at randomization, the majority had probably stopped seizing at the time of induction of hypothermia. Thus, the primary outcome pools the results of postseizure neuroprotection with those of successful treatment of refractory status epilepticus.

Lowering of intracranial pressure, the third potential benefit of hypothermia, may have biased the results for the $26 \%$ of patients who had potential mass lesions (hemorrhage, tumor, thrombosis, infection, or trauma).

We think that the HYBERNATUS trial still has much to teach us, most notably through separate analyses for patients with or without ongoing seizures.

\author{
Nicolas Engrand, M.D. \\ Stéphane Welschbillig, M.D. \\ Vera Dinkelacker, M.D., Ph.D. \\ Fondation Ophtalmologique Rothschild \\ Paris, France \\ nengrand@for.paris \\ No potential conflict of interest relevant to this letter was re-
} ported.

1. Legriel S, Lemiale V, Schenck M, et al. Hypothermia for neuroprotection in convulsive status epilepticus. N Engl J Med 2016; 375:2457-67.

2. Schmitt FC, Buchheim K, Meierkord H, Holtkamp M. Anticonvulsant properties of hypothermia in experimental status epilepticus. Neurobiol Dis 2006;23:689-96.

3. Vigué B, Ract C, Zlotine N, Leblanc PE, Samii K, Bissonnette B. Relationship between intracranial pressure, mild hypothermia and temperature-corrected $\mathrm{PaCO} 2$ in patients with traumatic brain injury. Intensive Care Med 2000;26:722-8.

DOI: 10.1056/NEJMc1700535

TO THE EDITOR: We noted some clinically relevant issues in the report by Legriel et al. First, the participants were patients in the intensive care unit (ICU), and body-mass index (BMI) was not taken into consideration when patients were assigned to the treatment groups, nor was there a post hoc analysis of outcomes according to BMI. In studies involving other cohorts of patients in the ICU, in-hospital mortality rates have been found to be lower among patients with a high BMI. ${ }^{1}$ Second, in our clinical practice, patients undergoing hypothermic treatment have been prone to pneumonia, and pneumonia related to hypothermia has been prolonged and hard to 